\title{
Glycemic variability as predictor of contrast-induced nephropathy in diabetic patients with acute myocardial infarction undergoing percutaneous coronary intervention
}

\author{
Pengfei Zuo, Yongjun Li, Zhi Zuo, Xin Wang, Genshan Ma \\ Department of Cardiology, Zhongda Hospital Affiliated to Southeast University, Nanjing, China \\ Contributions: (I) Conception and design: P Zuo, G Ma; (II) Administrative support: Y Li, G Ma; (III) Provision of study materials or patients: P Zuo, \\ Y Li; (IV) Collection and assembly of data: P Zuo, Z Zuo; (V) Data analysis and interpretation: P Zuo, X Wang; (VI) Manuscript writing: All authors; \\ (VII) Final approval of manuscript: All authors. \\ Correspondence to: Dr. Genshan Ma, PhD. Department of Cardiology, Zhongda Hospital Affiliated to Southeast University, 87 Dingjiaqiao Rd., \\ Nanjing, China. Email: genshanma@sina.com.
}

Background: Contrast-induced nephropathy (CIN) is a frequent complication in patients undergoing
percutaneous coronary intervention (PCI). Diabetes mellitus (DM) and acute myocardial infarction (AMI)
are associated with an increased risk of CIN. However, it remains unclear whether glycemic variability
$(\mathrm{GV})$ has the important prognostic significance of CIN in diabetic patients with AMI undergoing PCI.
We conducted this study to investigate the independent prognostic value of the in-hospital GV in diabetic
patients who presented with AMI and were treated with PCI.

Methods: The study group comprised 252 diabetic patients with AMI who underwent PCI and were assigned to CINand non-CIN groups. A continuous glucose monitoring system (CGMS) was used to determine the mean amplitude of glycemic excursion (MAGE), a representative index of GV. Independent risk factors for CIN were determined by multivariate logistic regression analysis (MLRA), and receiveroperating characteristic (ROC) analysis was used to measure the prognostic potential of GV.

Results: A total of 55 patients had CIN and they showed markedly elevated MAGE compared with the non-CIN group. MLRA revealed that MAGE had potential to independently predict CIN. The area under the ROC curve, optimal cut-point value, sensitivity and specificity for MAGE were 0.739, 2.95, 70.91\% and $61.42 \%$, respectively.

Conclusions: In diabetic AMI patients undergoing PCI, high GV is associated with increased risk of CIN.

Keywords: Contrast-induced nephropathy (CIN); glycemic variability (GV); mean amplitude of glycemic excursion (MAGE); percutaneous coronary intervention (PCI)

Submitted Sep 10, 2020. Accepted for publication Nov 18, 2020.

doi: 10.21037/atm-20-6968

View this article at: http://dx.doi.org/10.21037/atm-20-6968

\section{Introduction}

Contrast-induced nephropathy (CIN) refers to elevation of serum creatinine (SCr) following administration of contrast media. It is a frequent complication in patients undergoing percutaneous coronary intervention (PCI), and is linked to extended hospital stay and late adverse outcomes (1-3). In particular, AMI patients undergoing emergency PCI have a markedly accentuated risk of CIN compared with those undergoing elective PCI (4-6). However, apart from the recommendation to use intravenous hydration, there are no other precautions for preventing the occurrence of CIN (7). Therefore, effective and sensitive indicators are needed for timely detection and prevention of CIN, especially in individuals who are at high risk.

Diabetes mellitus (DM) is a major risk factor for coronary artery disease (CAD) (8), and dysglycemia is associated 
with poor outcomes in CAD patients. Increasing evidence demonstrates that hyperglycemia enhances the CIN risk after PCI $(9,10)$. It has been reported that the glycosylated hemoglobin $\left(\mathrm{HbA}_{1 \mathrm{c}}\right)$ level on admission is a useful marker of CIN in patients after coronary angiography or PCI $(11,12)$, but glycemic variability (GV; i.e., fluctuation in glucose level) is a more comprehensive and important component of dysglycemia than conventional indices that entail singlepoint measurements. The mean amplitude of glycemic excursion (MAGE) calculated using a continuous glucose monitoring system (CGMS) is an index of GV. A recent study showed that GV has prognostic potential regarding complications, including deterioration of renal function in patients with type $2 \mathrm{DM}$ (13). In addition, recent investigations have revealed that $\mathrm{GV}$, but not the average glucose concentration, is a risk factor for acute kidney injury (14), and a major risk for nephropathy. Previous studies have shown that blood glucose variability is closely related to the severity of coronary heart disease. Blood glucose variability is an independent determinant of the degree of coronary artery stenosis. The larger fluctuation of blood glucose indicated the more severe the degree of coronary artery stenosis.

However, not much is known about the prognostic value of GV for CIN in diabetic AMI patients undergoing PCI, so we investigated this issue. We present the following article in accordance with the STARD reporting checklist (available at http://dx.doi.org/10.21037/atm-20-6968).

\section{Methods}

\section{Patient population}

In this prospective observational study, 252 diabetic patients who presented with AMI and received drug-eluting stents in the Cardiology Department of Zhongda Hospital Affiliated to Southeast University between July 2015 and October 2018 were the subjects. They were assigned to two groups: CIN and non-CIN. In this study, AMI referred to presence of chest pain and elevated troponin I, in the presence or absence of ST-segment elevation on ECG; DM was detected in line with the criteria of American Diabetes Association. In addition, patients on insulin therapy or glucose-lowering medication were deemed diabetic. CIN was defined as an elevation in baseline $\mathrm{SCr}$ level $\geq 25 \%$ or an absolute elevation $\geq 44.2 \mu \mathrm{mol} / \mathrm{L}$ within 48-72 h after PCI. Coronary angioplasty was performed in the conventional manner, and coronary stents were used when required. Iodixanol (GE Healthcare, Cork, UK) was used as the contrast agent. All procedures performed in this study involving human participants were in accordance with the Declaration of Helsinki (as revised in 2013). The procedures used in this investigation were approved by the Medical Ethics Committee of Zhongda Hospital Affiliated to Southeast University. Informed consent was given by the patients.

\section{Exclusion criteria}

Patients who had diabetic ketosis, cardiac arrest requiring cardiopulmonary resuscitation, or end-stage renal disease requiring dialysis were excluded from the study. In addition, patients who were in a non-ketotic hyperosmolar coma, and those who had cardiogenic shock were excluded.

\section{Study protocol}

The baseline SCr level was tested before angiography. Regular SCr test during 2-3 days after PCI was performed to diagnose CIN. Routine measurements of glucose, cardiac troponin I (cTnI), blood urea nitrogen (BUN), low-density lipoprotein cholesterol (LDL-C), uric acid, albumin and hemoglobin were also carried out. The estimated glomerular filtration rate (eGFR) for each patient was calculated using the Modification of Diet in Renal Disease (MDRD) equation, and left ventricular ejection fraction (LVEF) was measured using echocardiography. Each participant had continuous CGMS monitoring for $72 \mathrm{~h}$ post-PCI with the range of detectable glucose fixed at $2.2-22.2 \mathrm{mmol} / \mathrm{L}$. Thus, any patient with data outside this range was excluded from the study. The data obtained using the CGMS were recorded and analyzed with CGMS software 3.0. The MAGE values were computed using a procedure described earlier (15).

\section{Statistical analysis}

Results are expressed as frequencies and percentages for categorical variables, and mean \pm SD for continuous variables. Statistical analysis was performed using SPSS 17.0 (SPSS Inc., Chicago, USA). Significant differences between groups were determined with Chi-square and unpaired $t$-tests. Risk factors for CIN were determined using multivariate logistic regression analysis (MLRA), and receiver-operating characteristic (ROC) analysis was used 
Table 1 Baseline clinical data for the two groups of diabetic patients

\begin{tabular}{|c|c|c|c|}
\hline Variable & CIN $(n=55)$ & Non-CIN (n=197) & $\mathrm{P}$ \\
\hline Age (years) & $68.15 \pm 1.34$ & $64.81 \pm 0.73$ & 0.033 \\
\hline BMI $\left(\mathrm{kg} / \mathrm{m}^{2}\right)$ & $24.45 \pm 0.33$ & $24.07 \pm 0.19$ & 0.350 \\
\hline Hypertension, n (\%) & $43(78.18)$ & $116(58.88)$ & 0.011 \\
\hline Smoking, n (\%) & $26(47.27)$ & $82(41.62)$ & 0.454 \\
\hline Family history of CAD, $\mathrm{n}(\%)$ & $10(18.18)$ & $27(13.71)$ & 0.407 \\
\hline Contrast dose (mL) & $107.45 \pm 3.94$ & $100.66 \pm 2.05$ & 0.125 \\
\hline Number of stents (n) & $1.38 \pm 0.07$ & $1.28 \pm 0.03$ & 0.144 \\
\hline \multicolumn{4}{|l|}{ Medications, n (\%) } \\
\hline Clopidogrel & $50(90.91)$ & $170(86.29)$ & 0.364 \\
\hline$\beta$-blocker & $40(72.73)$ & $160(81.22)$ & 0.169 \\
\hline Statin & 49 (89.09) & $184(93.40)$ & 0.284 \\
\hline ACEI/ARB & $32(58.18)$ & $129(65.48)$ & 0.117 \\
\hline CCB & $37(67.27)$ & $130(65.99)$ & 0.859 \\
\hline LMWH & $49(89.10)$ & $178(90.36)$ & 0.782 \\
\hline Insulin & $48(87.27)$ & $172(87.31)$ & 0.994 \\
\hline
\end{tabular}

Data are presented as mean \pm standard deviation, or as number (\%). ACEI, angiotensin-converting enzyme inhibitor; ARB, angiotensin receptor blocker, BMI, body mass index; CAD, coronary artery disease; CCB, calcium channel blocker; LMWH, low molecular weight heparin.

for determination of the predictive potential of MAGE. Statistical significance of differences was assumed at $\mathrm{P}<0.05$.

\section{Results}

\section{Baseline characteristics of the patients}

The cumulative incidence of CIN was $21.83 \%(\mathrm{n}=55 / 252)$ in the entire study population. The baseline patient characteristics and in-hospital medications are shown in Table 1. There were no significant differences between CIN and non-CIN groups regarding sex, body mass index, hyperlipidemia, smoking, family history of CAD, contrast dose, number of stents, and in-hospital medications $(\mathrm{P}>0.05)$. The CIN diabetic patients were markedly older $(68.15 \pm 1.34$ vs. $64.81 \pm 0.73$ years, $\mathrm{P}=0.033)$ and were significantly more hypertensive $(78.18 \%$ vs. $58.88 \%$, $\mathrm{P}=0.011)$ than patients in non-CIN group.

\section{Baseline laboratory test results}

The baseline laboratory data of the patients are shown in Table 2. The CIN patients had significantly higher levels of MAGE $(4.27 \pm 0.29$ vs. $2.77 \pm 0.12 \mathrm{mmol} / \mathrm{L}, \mathrm{P}<0.001)$, uric acid $(398.36 \pm 9.15$ vs. $373.95 \pm 5.42 \mathrm{mmol} / \mathrm{L}, \mathrm{P}=0.032)$, BUN $(8.94 \pm 0.35$ vs. $7.92 \pm 0.22 \mathrm{mmol} / \mathrm{L}, \mathrm{P}=0.025)$, and $\mathrm{SCr}(106.33 \pm 2.20$ vs. $99.92 \pm 1.24 \mu \mathrm{mol} / \mathrm{L}, \mathrm{P}=0.015)$ than those without CIN. Moreover, marked variations were observed in baseline eGFR $(60.13 \pm 2.02$ vs. $67.66 \pm$ $\left.1.22 \mathrm{~mL} / \mathrm{min} / 1.73 \mathrm{~m}^{2}, \mathrm{P}=0.003\right)$, LVEF $(49.89 \% \pm 1.36 \%$ vs. $53.82 \% \pm 0.72 \%, \mathrm{P}=0.011)$, and albumin $(33.20 \pm 0.65$ vs. $34.61 \pm 0.33 \mathrm{~g} / \mathrm{L}, \mathrm{P}=0.048)$ between the two groups. However, levels of baseline glucose, cTnI, hemoglobin and LDL-C $(\mathrm{P}>0.05)$ were comparable between the two groups.

\section{Logistic regression analysis}

The association of MAGE with the incidence of CIN 
Table 2 Baseline biochemical data for the two groups of diabetic patients

\begin{tabular}{|c|c|c|c|}
\hline Variable & $\operatorname{CIN}(n=55)$ & Non-CIN $(n=197)$ & $\mathrm{P}$ \\
\hline Glucose (mmol/L) & $12.59 \pm 0.85$ & $11.32 \pm 0.30$ & 0.083 \\
\hline LVEF (\%) & $49.89 \pm 1.36$ & $53.82 \pm 0.72$ & 0.011 \\
\hline cTnl ( $\mu \mathrm{g} / \mathrm{L})$ & $14.80 \pm 3.31$ & $10.35 \pm 1.47$ & 0.177 \\
\hline Albumin (g/L) & $33.20 \pm 0.65$ & $34.61 \pm 0.33$ & 0.048 \\
\hline LDL-C (mmoles $\cdot \mathrm{L}^{-1}$ ) & $2.50 \pm 0.09$ & $2.70 \pm 0.07$ & 0.136 \\
\hline Uric acid (mmoles $\left.\cdot \mathrm{L}^{-1}\right)$ & $398.36 \pm 9.15$ & $373.95 \pm 5.42$ & 0.032 \\
\hline BUN (mmol/L) & $8.94 \pm 0.35$ & $7.92 \pm 0.22$ & 0.025 \\
\hline
\end{tabular}

Data are presented as mean \pm standard deviation. BUN, blood urea nitrogen; eGFR, estimated glomerular filtration rate; LVEF, left ventricular ejection fraction; cTnl, cardiac troponin I; LDL-C, low-density lipoprotein cholesterol.

was studied using MRLA, with adjustments for age, hypertension, LVEF, albumin, uric acid, BUN, SCr and eGFR. Results of the analysis (Table 3) showed that MAGE [odds ratio $(\mathrm{OR})=1.521,95 \%$ confidence interval $(\mathrm{CI})$ $=1.282-1.805, \mathrm{P}<0.001]$ was markedly correlated with the incidence of CIN. In addition, hypertension $(\mathrm{OR}=0.4$, 95\% CI $=0.198-0.805, \mathrm{P}=0.01)$; LVEF $(\mathrm{OR}=0.964 ; 95 \%$ $\mathrm{CI}=0.933-0.995, \mathrm{P}=0.023)$; albumin $(\mathrm{OR}=0.926 ; 95 \%$ $\mathrm{CI}=0.86-0.997, \mathrm{P}=0.042)$; uric acid $(\mathrm{OR}=1.004 ; 95 \% \mathrm{CI}$ $=1-1.008, \mathrm{P}=0.034)$ and eGFR $(\mathrm{OR}=0.965,95 \% \mathrm{CI}=0.94-$ 0.991, $\mathrm{P}=0.007$ ) were independent determinants of $\mathrm{CIN}$.

\section{ROC curve for MAGE prediction of CIN}

As shown in Figure 1, the area under the ROC curve for MAGE was $0.739(95 \% \mathrm{CI}=0.662-0.817, \mathrm{P}<0.001)$. In addition, MAGE displayed significant predictive value for CIN in diabetic AMI patients undergoing PCI, and the optimum cut-point value of MAGE was 2.95, with sensitivity and specificity of $70.91 \%$ and $61.42 \%$, respectively.

\section{Discussion}

MAGE is considered as the "gold standard" for GV (16) and our results showed that elevated MAGE was independently associated with a high risk of CIN after PCI in AMI diabetic patients. This is the first report showing that GV is a powerful predictor of CIN in this group of cardiac patients.

$\mathrm{CIN}$ is an acute renal injury caused by contrast agents and is a frequent complication of PCI in patients with CAD. Moreover, DM is an important predisposing factor for CIN (17). Point-in-time blood glucose and $\mathrm{HbA}_{1 \mathrm{c}}$ are classical markers for assessing immediate and long-term glycometabolic status, respectively. Both hyperglycemia and elevated $\mathrm{HbA}_{1 \mathrm{c}}$ are associated with increased risk for CIN (9-12). However, compared with any of these traditional markers, $\mathrm{GV}$ is a more comprehensive and more sensitive maker of dysglycemia. Diabetic patients with comparable blood glucose or HbA1c profiles may have significant differences in GV (18), and the results of the present study were consistent with this finding. Severe glycemic excursion is more harmful than persistent hyperglycemia in the pathogenesis of cardiac adverse events $(16,19)$. Severe glycemic excursion leads to sympathetic dysfunction, which is associated with ischemic injury of the renal medulla through promotion of the secretion of cortisol and catecholamine (20). Glycemic excursion activates the nuclear factor- $\mathrm{\kappa B}$ and protein kinase $\mathrm{C}$ pathways, thereby aggravating inflammation (21-23). This is a critical step in the etiology of CIN (24). Glycemic excursion also induces oxidative stress, leading to kidney damage through overproduction of reactive oxygen species (ROS) $(16,25,26)$. Because GV is linked to these multifactorial events that are involved in the development of CIN, it could have a 
Table 3 Univariate and multivariate analyses for CIN predictors

\begin{tabular}{|c|c|c|c|c|c|c|}
\hline Variable & \multicolumn{3}{|c|}{ Univariate } & \multicolumn{3}{|c|}{ Multivariate } \\
\hline Age & 1.034 & $1.003-1.066$ & 0.034 & 1.016 & $0.961-1.074$ & 0.576 \\
\hline Hypertension & 0.334 & $0.159-0.699$ & 0.004 & 0.4 & $0.198-0.805$ & 0.01 \\
\hline MAGE & 1.485 & $1.248-1.767$ & $<0.001$ & 1.521 & $1.282-1.805$ & $<0.001$ \\
\hline Albumin & 0.928 & $0.865-0.996$ & 0.037 & 0.926 & $0.86-0.997$ & 0.042 \\
\hline Uric acid & 1.006 & $1.001-1.01$ & 0.009 & 1.004 & $1-1.008$ & 0.034 \\
\hline BUN & 1.109 & $0.994-1.238$ & 0.064 & - & - & - \\
\hline Creatinine & 1.022 & $1.004-1.04$ & 0.016 & 1.029 & $0.994-1.065$ & 0.103 \\
\hline
\end{tabular}

BUN, blood urea nitrogen; CIN, contrast-induced nephropathy; eGFR, estimated glomerular filtration rate; LVEF, left ventricular ejection fraction; MAGE, mean amplitude of glycemic excursion.

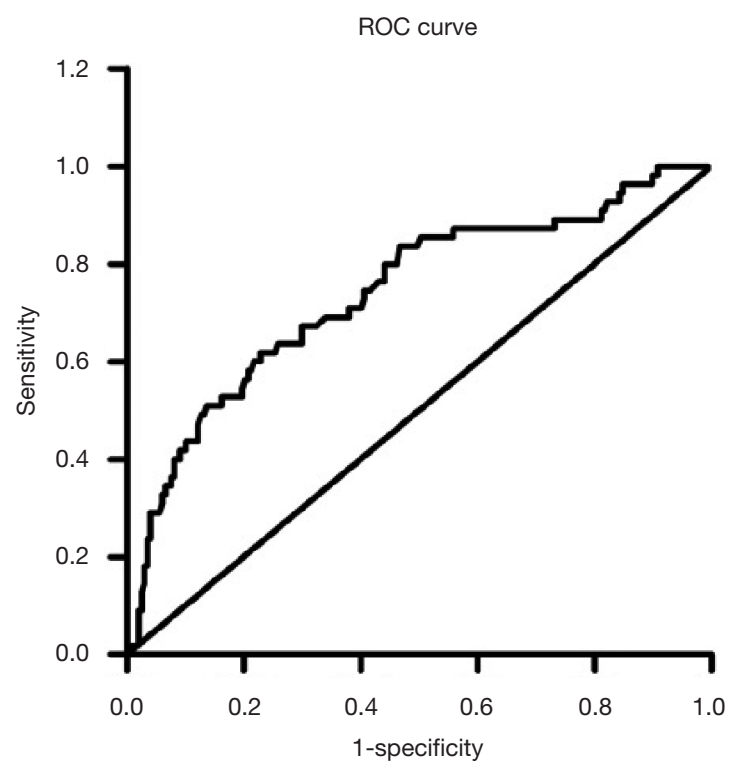

Figure 1 Area under the receiver-operating characteristic (ROC) curve analysis showing that mean amplitude of glycemic excursion has predictive potential for contrast-induced nephropathy.

powerful predictive effect for CIN, which was suggested by the results of this study. Further studies are needed to explore the specific mechanism by which GV is implicated in the etiology of CIN. Indeed, small sample size and single center are the limitations of this study. In the future, we need to use a multi-center study with a larger sample size to evaluate the correlation between blood glucose variability and contrast nephropathy, so as to further determine the predictive effect of blood glucose variability on contrast nephropathy.

Moreover, results from MLRA in the present investigation indicated that hypertension, LVEF, albumin, uric acid and eGFR are independent predisposing factors for CIN, which is are in agreement with those found by earlier studies (27-30).

\section{Conclusions}

We found that in diabetic AMI patients undergoing PCI, raised $G V$ was linked to increased risk of CIN, which suggests that GV has important prognostic significance in this group of CAD patients.

\section{Acknowledgments}

Funding: This work was supported by the Fundamental Research Funds for the Central Universities (grant No. 2242018K40155) and the Grant of Jiangsu Province Science and Technology Agency (grant No. BE2016785).

\section{Footnote}

Reporting Checklist: The authors have completed the STARD reporting checklist. Available at http://dx.doi.org/10.21037/ atm-20-6968

Data Sharing Statement: Available at http://dx.doi. 
org/10.21037/atm-20-6968

Conflicts of Interest: All authors have completed the ICMJE uniform disclosure form (available at http://dx.doi. org/10.21037/atm-20-6968). The authors have no conflicts of interest to declare.

Ethical Statement: The authors are accountable for all aspects of the work in ensuring that questions related to the accuracy or integrity of any part of the work are appropriately investigated and resolved. All procedures performed in this study involving human participants were in accordance with the Declaration of Helsinki (as revised in 2013). The procedures used in this investigation were approved by the Medical Ethics Committee of Zhongda Hospital Affiliated to Southeast University. Informed consent was given by the patients.

Open Access Statement: This is an Open Access article distributed in accordance with the Creative Commons Attribution-NonCommercial-NoDerivs 4.0 International License (CC BY-NC-ND 4.0), which permits the noncommercial replication and distribution of the article with the strict proviso that no changes or edits are made and the original work is properly cited (including links to both the formal publication through the relevant DOI and the license). See: https://creativecommons.org/licenses/by-nc-nd/4.0/.

\section{References}

1. McCullough PA. Contrast-induced nephropathy: definitions, epidemiology, and implications. Interv Cardiol Clin 2014;3:357-62.

2. Abe M, Morimoto T, Akao M, et al. Relation of contrastinduced nephropathy to long-term mortality after percutaneous coronary intervention. Am J Cardiol 2014;114:362-8.

3. Tsai TT, Patel UD, Chang TI, et al. Contemporary incidence, predictors, and outcomes of acute kidney injury in patients undergoing percutaneous coronary interventions: insights from the NCDR Cath-PCI registry. JACC Cardiovasc Interv 2014;7:1-9.

4. Ueda H, Yamada T, Masuda M, et al. Prevention of contrast-induced nephropathy by bolus injection of sodium bicarbonate in patients with chronic kidney disease undergoing emergent coronary procedures. Am J Cardiol 2011;107:1163-7.

5. De Filippo O, D’Ascenzo F, Piroli F, et al. Sometimes neither water nor fire are more useful than friendshipa new risk score for prediction of contrast-induced nephropathy (CIN) and long-term adverse outcomes in patients undergoing coronary angiography. J Thorac Dis 2019;11:2675-9.

6. Marenzi G, Assanelli E, Campodonico J, et al. Contrast volume during primary percutaneous coronary intervention and subsequent contrast-induced nephropathy and mortality. Ann Intern Med 2009;150:170-7.

7. StephanWindecker, Kolh P, Alfonso F, et al. 2014 ESC/ EACTS guidelines on myocardial revascularization. Rev Esp Cardiol (Engl Ed) 2015;68:144.

8. Beckman JA, Paneni F, Cosentino F, et al. Diabetes and vascular disease: pathophysiology, clinical consequences, and medical therapy: part II. Eur Heart J 2013;34:2444-52.

9. Marenzi G, De Metrio M, Rubino M, et al. Acute hyperglycemia and contrast-induced nephropathy in primary percutaneous coronary intervention. Am Heart J 2010;160:1170-7.

10. Stolker JM, McCullough PA, Rao S, et al. Pre-procedural glucose levels and the risk for contrast-induced acute kidney injury in patients undergoing coronary angiography. J Am Coll Cardiol 2010;55:1433-40.

11. Barbieri L, Verdoia M, Schaffer A, et al. Pre-diabetes and the risk of contrast induced nephropathy in patients undergoing coronary angiography or percutaneous intervention. Diabetes Res Clin Pract 2014;106:458-64.

12. Qin YH, Yan GL, Ma CL, et al. Effects of hyperglycaemia and elevated glycosylated haemoglobin on contrastinduced nephropathy after coronary angiography. Exp Ther Med 2018;16:377-83.

13. Cardoso CRL, Leite NC, Moram CBM, et al. Long-term visit-to-visit glycemic variability as predictor of microand macrovascular complications in patients with type 2 diabetes: The Rio de Janeiro Type 2 Diabetes Cohort Study. Cardiovasc Diabetol 2018;17:33.

14. Nam K, Jeon Y, Kim WH, et al. Intraoperative glucose variability, but not average glucose concentration, may be a risk factor for acute kidney injury after cardiac surgery: a retrospective study. Can J Anaesth 2019;66:921-33.

15. Service FJ, Molnar GD, Rosevear JW, et al. Mean amplitude of glycemic excursions, a measure of diabetic instability. Diabetes 1970;19:644-55.

16. Monnier L, Mas E, Ginet C, et al. Activation of oxidative stress by acute glucose fluctuations compared with sustained chronic hyperglycemia in patients with type 2 diabetes. JAMA 2006;295:1681-7.

17. Sudarsky D, Nikolsky E. Contrast-induced nephropathy 
in interventional cardiology. Int J Nephrol Renovasc Dis 2011;4:85-99.

18. Monnier L, Colette C, Owens D. The glycemic triumvirate and diabetic complications: is the whole greater than the sum of its component parts? Diabetes Res Clin Pract 2012;95:303-11.

19. Ceriello A, Esposito K, Piconi L, et al. Oscillating glucose is more deleterious to endothelial function and oxidative stress than mean glucose in normal and type 2 diabetic patients. Diabetes 2008;57:1349-54.

20. Takei Y, Tomiyama H, Tanaka N, et al. Close relationship between sympathetic activation and coronary microvascular dysfunction during acute hyperglycemia in subjects with atherosclerotic risk factors. Circ J 2007;71: 202-206.

21. Yamazaki M, Hasegawa G, Majima S, et al. Effect of repaglinide versus glimepiride on daily blood glucose variability and changes in blood inflammatory and oxidative stress markers. Diabetol Metab Syndr 2014;6:54.

22. Otsuka A, Azuma K, Iesaki T, et al. Temporary hyperglycaemia provokes monocyte adhesion to endothelial cells in rat thoracic aorta. Diabetologia 2005;48:2667-74.

23. Azuma K, Kawamori R, Toyofuku Y, et al. Repetitive fluctuations in blood glucose enhance monocyte adhesion to the endothelium of rat thoracic aorta. Arterioscler Thromb Vasc Biol 2006;26:2275-80.

24. McCullough PA. Contrast-induced acute kidney injury. J Am Coll Cardiol 2008;51:1419-28.

25. Johnson EL. Glycemic variability in type 2 diabetes

Cite this article as: Zuo $\mathrm{P}, \mathrm{Li} \mathrm{Y}$, Zuo Z, Wang X, Ma G. Glycemic variability as predictor of contrast-induced nephropathy in diabetic patients with acute myocardial infarction undergoing percutaneous coronary intervention. Ann Transl Med 2020;8(22):1505. doi: 10.21037/atm-20-6968 mellitus: oxidative stress and macrovascular complications. Adv Exp Med Biol 2012;771:139-54.

26. Quagliaro L, Piconi L, Assaloni R, et al. Intermittent high glucose enhances apoptosis related to oxidative stress in human umbilical vein endothelial cells: the role of protein kinase $\mathrm{C}$ and $\mathrm{NAD}(\mathrm{P}) \mathrm{H}$-oxidase activation. Diabetes 2003;52:2795-804.

27. Tang C, Hou J, Yan G, et al. Effects of Serum Cytochrome c on Contrast-Induced Nephropathy in Patients with ST-Elevation Myocardial Infarction Undergoing Percutaneous Coronary Intervention. Biomed Res Int 2019;2019:9357203.

28. Zhu B, Hou J, Gong Y, et al. Association between Serum Ferritin and Contrast-Induced Nephropathy in Patients with Acute Coronary Syndrome Undergoing Percutaneous Coronary Intervention. Biomed Res Int 2016;2016:5420345.

29. Goksuluk H. The Effect of renin-angiotensin system blocking agents on the risk of contrast-induced nephropathy and early defection with neutrophil gelatinase-associated lipocalin in diabetic patients undergoing coronary procedures. Acta Med Mediterr 2019;35:187-92.

30. Isler Y, Ozdinc S, Kaya H. Can Ngal be Used as an Early Marker of Contrast-Induced Nephropathy in Emergency Department. Acta Med Mediterr 2018;34:1889-94.

(English Language Editor: K. Brown) 